\title{
Compensation of the Postural Instability in Patients with Acute Unilateral Vestibular Neuritis: The Usefulness of Computerized Dynamic Posturography as an Objective Indicator
}

\author{
Jin Woo Park, Yong Gook Shin, Ja Won Gu, Mee Hyun Song, and Dae Bo Shim \\ Department of Otorhinolaryngology, Myongji Hospital, Seonam University College of Medicine, Goyang, Korea
}

\begin{abstract}
급성 일측성 전정신경염 환자에서 자세불안정의 회복: 객관적 지표로서 컴퓨터 동적자세검사의 유용성
박진우 · 신용국 · 구자원 · 송미현 · 심대보

서남대학교 의과대학 명지병원 이비인후과학교실
\end{abstract}

Received April 18, 2017

Revised May 11, 2017

Accepted May 23, 2017

Address for correspondence

Dae Bo Shim, MD, PhD

Department of Otorhinolaryngology,

Myongji Hospital,

Seonam University

College of Medicine,

55 Hwasu-ro 14beon-gil,

Deogyang-gu, Goyang 10475, Korea

Tel +82-31-810-5451

Fax +82-31-969-0500

E-mail lovend77@gmail.com
Background and Objectives The aim of this study was to evaluate the usefulness of computerized dynamic posturography (CDP) in patients with acute vestibular neuritis (AVN) by identifying the recovery period of Sensory Organization Test (SOT) and comparing the result of SOT with those of the vestibulo-ocular reflex (VOR) tests and subjective symptoms.

Subjects and Method A prospective study was conducted on 41 patients who were diagnosed with AVN. The SOT was measured daily until the equilibrium composite score recovered the normal value. A survey, composing of questionnaires on Visual Analogue Scale (VAS), Dizziness Handicap Inventory (DHI), motion sensitive quotient (MSQ) and Activities-Specific Balance Confidence Scale (ABC), was conducted on the patient's initial visit and on the day the normal value of SOT was recovered. Videonystagmography and the caloric test were also performed, and the results were compared with those of the SOT.

Results The mean duration from the onset of vertigo to the recovery of SOT scores was $3.7 \pm$ 2.9 days (median 3.0 days) and that from the onset of vertigo to the disappearance of spontaneous nystagmus was $17.1 \pm 27.2$ days (median 6.0 days). The scores of 4 questionnaires (VAS, DHI, MSQ, and ABC) were significantly different between the initial day and the day of recovery to the normal value of SOT $(p<0.001)$. However, the velocity of spontaneous nystagmus on the initial visit and the degree of canal paresis from the caloric test showed no significant correlations to recovery duration from the onset of vertigo to the normalization of SOT score.

Conclusion The recovery duration of vestibulospinal reflex (VSR) is much shorter than that of VOR in patients with AVN. The recovery of subjective symptoms showed close correlation with the recovery of VSR, but the results of VSR was not correlated with that of VOR. Therefore, CDP could be a very useful test for monitoring the resolution of subjective symptoms in patients with AVN.

Korean J Otorhinolaryngol-Head Neck Surg 2017;60(6):295-300

Key Words Sensory organization test · Vestibular neuritis · Vestibuloocular reflex · Vestibulospinal reflex.

This is an Open Access article distributed under the terms of the Creative Commons Attribution Non-Commercial License (http://creativecommons.org/licenses/by-nc/4.0) which permits unrestricted non-commercial use, distribution, and reproduction in any medium, provided the original work is properly cited. 


\section{서 론}

급성 전정신경염(acute vestibular neuritis, $\mathrm{AVN}$ )은 급성 일측성 말초성 전정장애 중 대표적인 질환의 하나로 지속적인 현훈, 병변의 반대측으로 향하는 자발안진, 온도안진검사에서 일측성 반고리관 마비, 그리고 와우 증상이 없는 경우 $\mathrm{AVN}$ 으로 진단한다. ${ }^{1-3)} \mathrm{AVN}$ 환자들을 진단할 때 사용하는 전정기능검 사는 비디오안진검사 및 온도안진검사와 같이 주로 안진을 이 용하여 전정안반사(vestibulo-ocular reflex)를 평가하는 검사 들과 전정경부반사(vestibulocollic reflex)를 평가하는 경부 전 정유발근전위검사, 전정척수반사(vestibulospinal reflex)를 평 가하는 컴퓨터 동적자세검사(computerized dynamic posturography, $\mathrm{CDP}$ )가 있다. ${ }^{4.5)} \mathrm{CDP}$ 는 신체의 평형 유지에 필요한 시 각, 체성감각, 전정감각을 조합하여, 선별적 및 종합적으로 자 세 유지 기능의 지각계와 운동계의 기능을 평가하는 검사로 임상에 많이 사용되고 있으며, 특히 감각구성검사(Sensory Organization Test, SOT)를 통해 어지럼 환자에서 자세불안정 에 관여하는 감각계의 손상을 평가한다. ${ }^{6}$

$\mathrm{AVN}$ 환자는 급성기에 현훈 외에도, 다양한 정도의 자세의 불안정과 보행장애를 호소한다. ${ }^{3)}$ 기존에 적용되어 온 $\mathrm{AVN}$ 의 진단기준은 전정안반사를 평가하는 전정기능검사에 치우쳐 이러한 자세의 불안정이나 보행장애의 평가를 시행하는 것은 강조되지 않았다. $\mathrm{CDP}$ 는 이러한 자세불안정을 평가하는 데 유 용한 검사지만, $\mathrm{AVN}$ 에서 그 임상적 유용성을 평가한 연구가 부족하다. 또한, 어지럼의 주관적 증상을 정량화하기 위해 많 은 설문지들을 사용하고 있는데, 어지럼장애척도(Dizziness Handicap Inventory, DHI)는 비디오안진검사나 회전검사 등 과 같은 전정기능검사로는 알 수 없는 어지럼 환자의 주관적 증상과 불편함을 객관적으로 정량화하거나 치료 결과를 객관 적으로 평가하기 위한 목적으로 개발되어 사용되고 있고, 자세 불안정의 평가에는 활동별균형자신감척도(Activities-Specific Balance Confidence Scale, $\mathrm{ABC}$ ), 동작민감도지수(motion sensitivity quotient, MSQ)가 사용되고 있다.-9) 기존 $\mathrm{AVN}$ 환자들에서 진행된 연구로 Fetter 등이은 $\mathrm{CDP}$ 를 통한 결과 로 급성 전정질환 환자들에서 자세불안정의 회복이 1 2주 내로 일어난다고 하였다. 그러나 이 연구는 대상환자 수가 10 명으로 매우 적었고, $\mathrm{CDP}$ 를 연속적으로 시행하지 않은 문제 점이 있었다. 다른 연구에서 전정안반사를 이용한 전정기능검 사와 설문지 $(\mathrm{DHI})$ 를 이용한 주관적 증상 변화 사이에 통계 학적으로 의미 있는 상관관계를 보였지만, ${ }^{11)}$ 아직까지 AVN 환자들에서 주관적 증상과 전정척수반사와의 연관성이나 전 정척수반사와 전정안반사의 상관관계를 분석한 연구는 부족 하다.
저자들은 $\mathrm{AVN}$ 환자에서 자세불안정의 객관적 평가를 위한 $\mathrm{CDP}$ 의 유용성을 확인하기 위해 $\mathrm{SOT}$ 결과의 자연경과를 확 인하였고, SOT의 총합점수(composite score)를 설문지를 통 한 주관적 증상의 호전 및 전정안반사의 지표들과 비교 분석 함으로써 $\mathrm{AVN}$ 에서 전정척수반사와 전정안반사 및 주관적 증 상 간의 상관관계를 확인하였다.

\section{대상 및 방법}

\section{대 상}

2013년 9월부터 2015년 8월까지 본원 응급실 및 외래를 통 해 어지럼을 주소로 내원하여 $\mathrm{AVN}$ 으로 진단된 환자들을 대 상으로 전향적 연구를 진행하였다. 본 연구의 대상은 다음과 같은 조건을 만족할 때 $\mathrm{AVN}$ 으로 진단하였다. 1) 급성으로 발생한 현훈이 주 증상이고, 2) 병변의 반대측을 향하는 자발 안진, 3) 온도안진검사에서 병변측의 반고리관 마비 정도가 $25 \%$ 이상일 때, 4) 난청이나 이명의 청각증상이 없고, 5) 뇌 자기공 명영상검사에서 이상소견이 없는 경우에 연구에 포함하였다. 본 연구에서 모든 환자들은 내원일부터 5일 동안 정맥주사로 고용량 스테로이드(dexamethasone $0.15 \mathrm{mg} / \mathrm{kg} / \mathrm{day}$ )를 사용 하였고, 이후 5 일간 용량을 반감하여 총 10 일간 스테로이드 치료를 시행하였다. 모든 환자들에서 어지럼 증상 조절을 위 해 어지럼의 정도와 상관없이 경구 약물치료(betahistine mesylate $48 \mathrm{mg} / \mathrm{day}$ )를 병행하였으며, SOT의 결과가 정상이 되 었을 때 전정재활치료를 시작하였다. 본 연구는 서남대학교 명지병원 임상시험위원회(Institutional Review Board, NO. 13-047)의 윤리기준에 부합하게 진행되었다.

\section{감각구성검사(Sensory Organization Test, SOT)}

$\mathrm{AVN}$ 으로 진단된 환자들을 대상으로 첫 진단한 시점부터 CDP(EquiTest; NeuroCom International Inc., Clackamas, $\mathrm{OR}, \mathrm{USA}$ )를 이용하고, $\mathrm{SOT}$ 를 매일 시행하여 자연경과를 확 인하였다. SOT는 체성감각을 선택적으로 자극하기 위해 발 판의 움직임 여부와 시각의 선택적 자극을 위해 정상시각, 폐 안, 혼동시각을 조합하여 여섯 조건의 검사를 하는 것으로 구성된다. 조건 $1,2,3$ 은 고정된 지지면에서 각각 정상시각, 폐안, 혼동시각으로 검사하여 평형의 유지에 정상시각이 필 요한지와 부적절한 시각의 영향을 억제할 수 있는지 검사하 였다. 조건 $4,5,6$ 은 움직이는 지지면에서 각각 정상시각, 폐 안, 혼동시각으로 검사하여 비교하였으며, 조건 5,6 은 시각과 체성감각의 혼동으로 정확한 전정감각의 역할만을 검사하였 다. 평형점수(equilibrium score)는 전후 방향에서 발목관절을 중심으로 평형을 유지할 수 있는 최대 한계인 약 12.5 도 이상 
의 동요를 0점으로 설정하고, 완전한 평형이 유지되어 동요가 없을 때를 100점으로 환산한 점수로, 각 조건에서 1회에 20초 씩, 3회씩 실시하였다. 총합점수(composite score)는 각 조건 의 평형점수의 총합을 총 시행한 검사횟수로 나눈 것으로 균 형 장애의 정도를 알 수 있는 점수이다.

첫 진단 시점에서 시행한 SOT의 조건 5와 6이 정상이거나, 총합점수가 정상인 환자는 연구의 대상에서 제외하였다. 첫 진단 시, SOT의 총점이 비정상인 환자들은 매일 총합점수를 확인하여 정상이 된 시점까지의 평균 기간을 확인하였다.

\section{어지럼 증상 평가(설문지)}

어지럼의 주관적 평가를 위해 시각상사척도(Visual Analogue Scale, $\mathrm{VAS}), \mathrm{DHI}, \mathrm{MSQ}, \mathrm{ABC}$ 를 포함한 네 가지 설문지를 첫 진단일과 $\mathrm{SOT}$ 의 총점이 정상값으로 회복된 시점에 시행하 여 주관적인 어지럼의 회복 양상을 확인하였다.

$\mathrm{DHI}$ 는 2004년 대한평형의학회에서 한국어로 번역한 설문 지를 사용하였다. ${ }^{21}$ 환자의 물리적(7문항), 감정적(9문항), 기 능적(9문항)인 세 환경에서 어지럼에 의한 활동의 제약을 설 문조사를 통해 빈도순으로 빈번할 경우 4점에서 0 점까지 부 여한 후 합산하여 최대 제약 시에 100점을, 전혀 제약이 없을 시에는 0 점을 부여하였다. MSQ는 선 자세(2문항), 앉은 자세 (13문항), 자세 변화(4문항)에서 어지럼이 유발되는지를 묻고 가장 심할 경우 3 점을, 전혀 유발되지 않을 경우 0 점을 부여 해서 합산한 후에 최대 제약 시에 57점을, 전혀 제약이 없을 시 에는 0점을 부여하였다. ${ }^{13)} \mathrm{ABC}$ 는 2004년 대한평형의학회에 서 한국어로 번역한 설문지를 사용하였고, 일상생활에서 흔히 접하게 되는 상황(16문항)에서 행동에 전혀 자신 없는 경우 0 점부터 완전히 자신 있는 경우 100 점까지 순차적으로 점수를 부여하여 점수의 합을 최대 1600 점부터 최소 0 점까지 부여하 였다. ${ }^{12)}$

\section{전정안반사(Vestibulo-ocular reflex, VOR)의 평가}

전정안반사의 평가를 위해 진단일부터 비디오안진검사 (SLMED, Seoul, Korea)를 시행하여 초기 자발안진의 강도와 자발안진이 사라지는 시점까지 걸리는 기간을 확인하였다. 퇴 원 시, 안진이 남아 있는 환자들은 퇴원 후 1 주일마다 외래 를 통해 경과관찰을 시행하여 안진의 회복을 확인하였다. 온 도안진검사는 내원 3일 이내에 시행하여 병변측 반고리관 마 비의 크기를 확인하였다.

\section{통계학적 방법}

$\mathrm{SOT}$ 의 호전기간과 자발안진이 사라지는 기간을 비교하기 위해 Mann-Whitney U test를 시행하였다. 전정척수반사와
전정안반사(안진의 강도, 안진의 회복기간, 반고리관 마비의 정도)의 상관관계를 알아보기 위해 linear regression analysis 를 시행하였고, SOT의 총합점수 회복에 따른 주관적 증상(설 문지 점수)의 상관관계를 알아보기 위해 independent t-test 를 시행하였다. 통계학적 처리는 SPSS version 18.0(SPSS Inc., Chicago, IL, USA)을 이용하였고, $p$ 값이 0.05 미만인 경우를 통계학적으로 의미 있는 것으로 해석하였다.

\section{결 과}

본 연구에서 AVN으로 진단된 환자는 총 62 명이었으며 처 음 시행한 SOT의 결과값이 정상인 21명을 제외하여, 총 41명 의 환자를 대상으로 전향적 연구를 시행하였다. 전체 41 명의

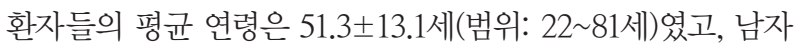
20 명, 여자 21 명으로 성비의 차이는 보이지 않았으며, 병변의 방향은 우측이 22 명, 좌측이 19 명이었다. 대상환자들의 초기 검사 결과값들은 Table 1과 같았다. 대상환자들의 증상이 발

Table 1. Clinical characteristics

\begin{tabular}{|c|c|}
\hline Variable & Value \\
\hline Age $($ mean $\pm S D)$ & $51.3 \pm 13.1$ \\
\hline Sex (male:female) & $20: 21$ \\
\hline Affected side (right:left) & $22: 19$ \\
\hline Canal paresis on affected side $(\%$, mean \pm SD $)$ & $56.8 \pm 28.9$ \\
\hline $\begin{array}{l}\text { Degree of spontaneous nystagmus } \\
\text { (degree/second, mean } \pm \text { SD) }\end{array}$ & $19.1 \pm 11.5$ \\
\hline \multicolumn{2}{|l|}{ Composite score of SOT (mean \pm SD) } \\
\hline Day of initial visit & $52.9 \pm 9.8$ \\
\hline Day of SOT normalization & $76.9 \pm 4.1$ \\
\hline
\end{tabular}

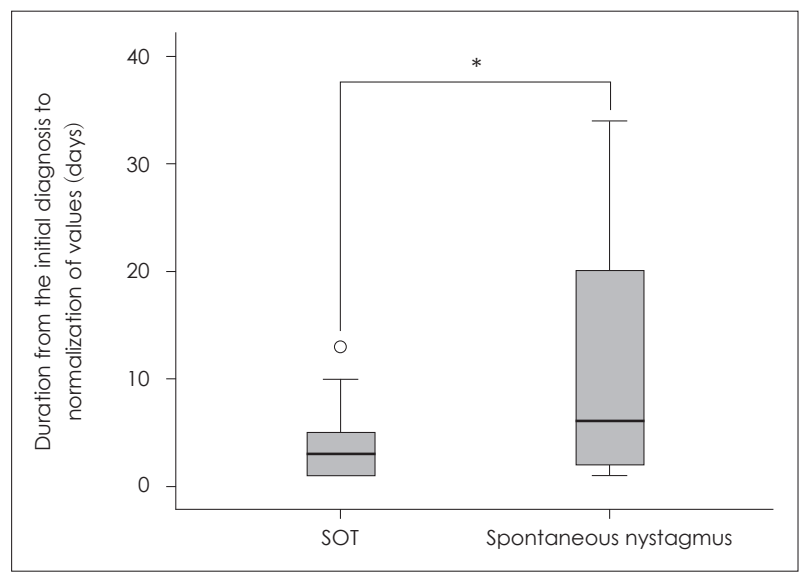

Fig. 1. Comparison of the recovery duration between the Sensory Organization Test (SOT) and spontaneous nystagmus. The duration from the initial diagnosis to normalization of SOT scores $(3.7 \pm 2.9$ days) was much shorter than that of the spontaneous nystagmus $(17.1 \pm 27.2$ days $)\left({ }^{*} p=0.001\right)$. 
생한 시점부터 SOT의 총점이 정상으로 회복된 시점까지의 평균 기간은 $3.7 \pm 2.9$ 일(중앙값 3.0 일)로 자발안진이 정상으로 회복될 때까지의 평균 기간인 $17.1 \pm 27.2$ 일(중앙값 6.0 일)보다 매우 짧았다 $(p=0.001)$ (Fig. 1).

$\mathrm{SOT}$ 의 총점이 정상값으로 회복된 기간과 온도안진검사에

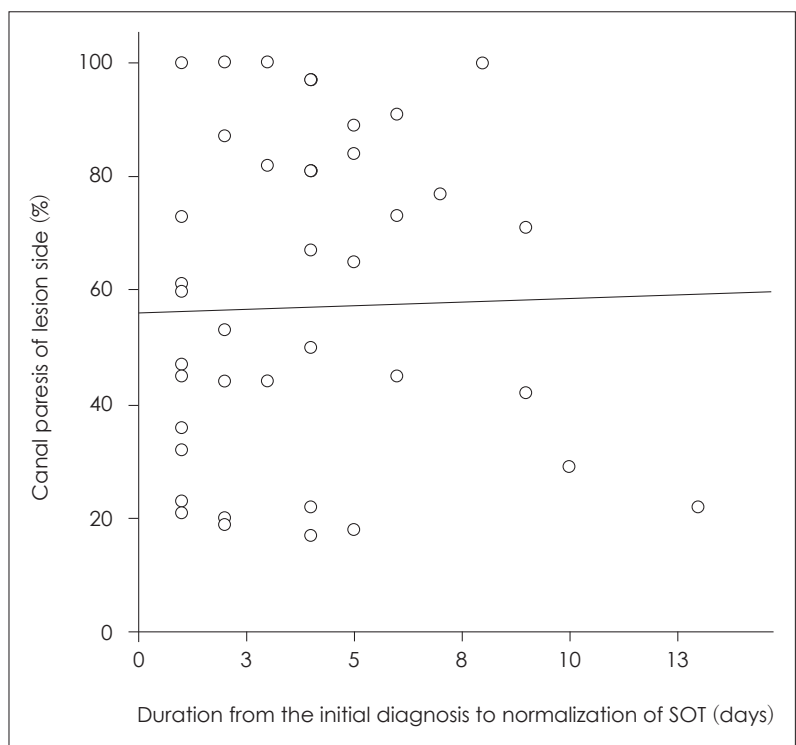

Fig. 2. Relationship between the degree of canal paresis of the lesion ear on the caloric test and the duration from the initial diagnosis to the normalization of Sensory Organization Test (SOT). The vestibulospinal reflex measurement (the duration from the initial diagnosis to the normalization of SOT) was not correlated with the vestubulo-ocular reflex measurement (the degree of canal paresis of the lesion ear on the caloric test) $\left(R^{2}=0.039\right)$.
서 반고리관 마비 정도 사이의 유의한 상관관계는 관찰되지 않았다 $\left(\mathrm{R}^{2}=0.039\right)$ (Fig. 2). 또한, $\mathrm{SOT}$ 의 총점이 정상값으로 회복된 기간과 초기 자발안진의 강도 및 자발안진이 사라진 시점까지의 기간과의 관계에서도 유의한 상관관계를 보이지 않았다(각각 $\mathrm{R}^{2}=0.028, \mathrm{R}^{2}=0.01$ )(Fig. 3). 초기 SOT의 총점이 높을수록 SOT의 회복속도가 짧은 경향성을 확인할 수 있었

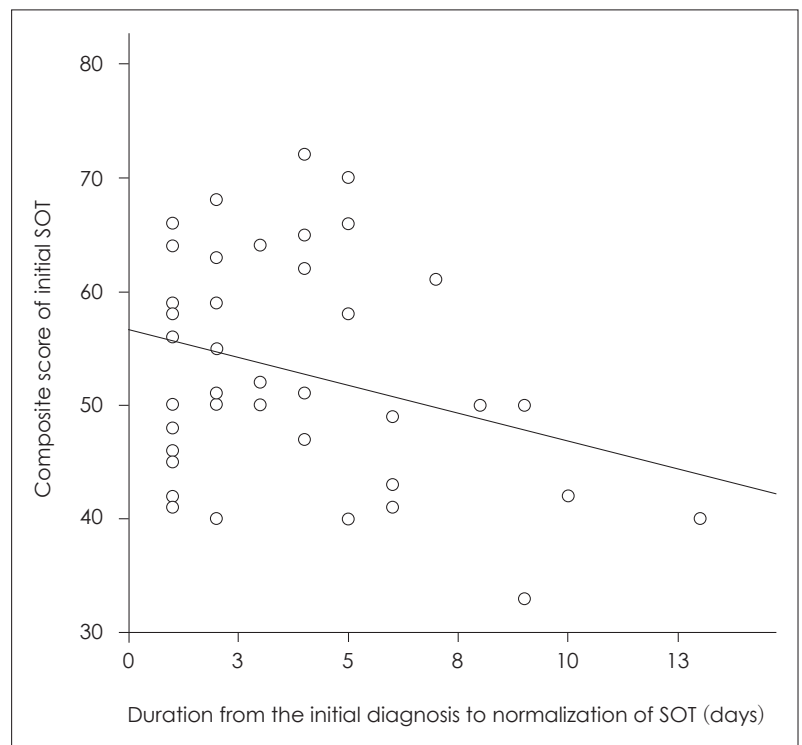

Fig. 4. Relationship between the initial composite score of Sensory Organization Test (SOT) and the duration from the initial diagnosis to the normalization of SOT. There was no correlation between the duration from the initial diagnosis to the normalization of SOT and the initial composite score of SOT $\left(R^{2}=0.088, p=0.06\right)$.

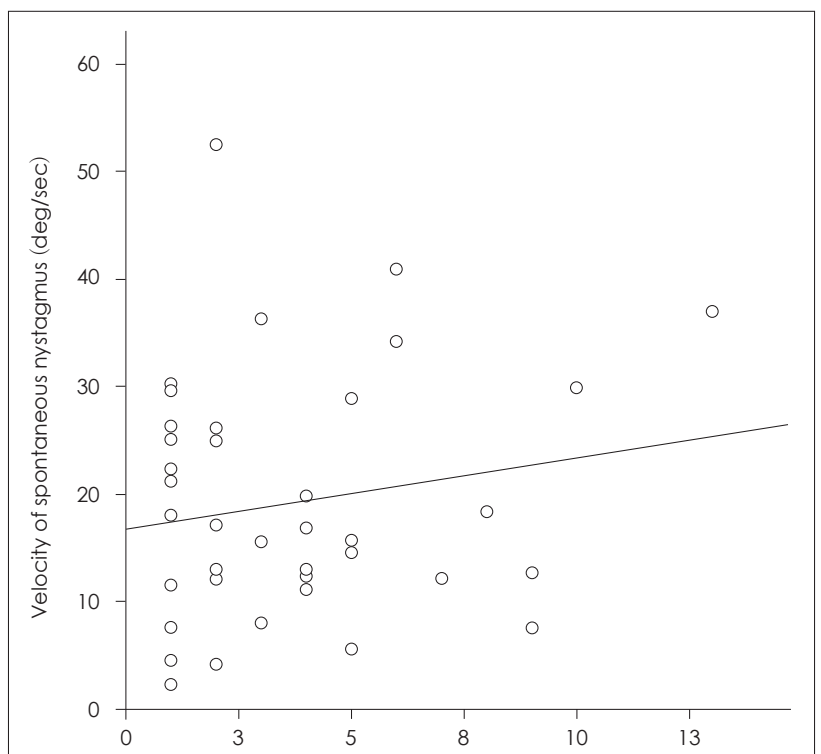

A Duration from the initial diagnosis to normalization of SOT (days)

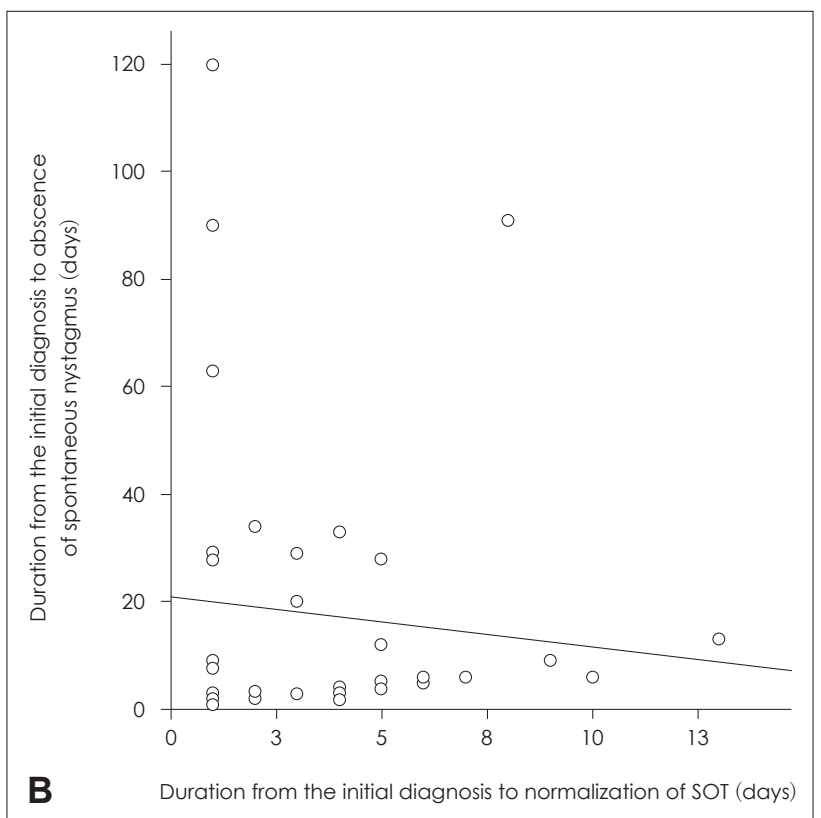

B Duration from the initial diagnosis to normalization of SOT (days)

Fig. 3. Relationship between the duration from the initial diagnosis to the normalization of Sensory Organization Test (SOT) and the parameters of spontaneous nystagmus. There was no correlation between the duration from the initial diagnosis to the normalization of SOT and the velocity of initial spontaneous nystagmus $\left(R^{2}=0.028\right)(A)$. The duration from the initial diagnosis to the normalization of SOT was not correlated with the duration from the initial diagnosis to the disappearance of spontaneous nystagmus $\left(R^{2}=0.01\right)(B)$. 
The Usefulness of Computerized Dynamic Posturography in Acute Vestibular Neuritis I Park JW, et al.

Table 2. Comparison of the various questionnaires (VAS, DHI, MSQ, and ABC) between the day of initial visit and the day of recovery to the normal value of SOT

\begin{tabular}{lccc}
\hline \multicolumn{1}{c}{ Questionnaires } & Day of initial visit & Day of normal SOT & p-value \\
\hline Visual Analogue Scale (VAS) & $6.9 \pm 1.4$ & $2.5 \pm 1.4$ & $<0.001^{*}$ \\
Dizziness Handicap Inventory (DHI) & $44.8 \pm 22.6$ & $17.2 \pm 15.3$ & $<0.001^{*}$ \\
Motion sensitivity quotient (MSQ) & $41.1 \pm 14.8$ & $13.1 \pm 10.3$ & $<0.001^{*}$ \\
Activities-Specific Balance Confidence Scale (ABC) & $408.5 \pm 242.8$ & $1094.6 \pm 276.0$ & $<0.001^{*}$ \\
\hline
\end{tabular}

*independent t-test. SOT: Sensory Organization Test

으나, 통계적으로 유의한 상관관계를 보이지는 않았다 $\left(\mathrm{R}^{2}=\right.$ 0.088, $p=0.06$ )(Fig. 4).

마지막으로, 어지럼의 주관적 평가를 위해 첫 진단 시점과 $\mathrm{SOT}$ 의 총점이 정상값으로 회복된 시점에 시행한 설문지의 점 수 비교 결과, 모든 설문지 점수들은 두 시점에서 통계학적으 로 유의한 차이를 보였다(Table 2).

\section{고 찰}

본 연구에서 전정척수반사를 확인하는 SOT의 호전기간이 자발안진의 호전기간보다 현저히 짧았다. 전정척수반사는 가 쪽전정척수로와 안쪽전정척수로를 통하여 근육의 긴장을 조 절하고 머리와 몸의 반사적인 자세 유지에 관여한다. 가쪽전 정척수로는 대부분 가쪽전정신경핵에서 기원하여 동측 척수 의 모든 분절로 투사된다. 앞반고리관 및 뒤반고리관, 이석기 관, 전정소뇌의 정보를 받아 척수의 여러 분절의 곁가지를 내 고 여러 근육군의 활동을 통합하여 자세를 조절한다. 안쪽전 청척수로는 대부분 안쪽전정신경핵에서 기원하며 전정 수용 체와 소뇌로부터 정보를 받아 경부의 굴곡근 및 신전근의 신 경원을 지배하여 공간에서 머리를 안정시키는 전정목반사에 관여한다. ${ }^{14)}$ 이에 반해, 전정안반사는 주로 위전정신경핵과 안쪽전정신경핵을 경유하여 이루어지는데, 전정계의 자극이 나 시각의 자극으로 유발되어 전정신경핵과 그물체를 경유하 여 안구운동에 관여하는 흥분 및 억제 정보가 제 $3,4,5$ 뇌신 경핵으로 전달된다. ${ }^{15)}$ 본 연구 대상에서 $\mathrm{AVN}$ 의 진단기준은 온도안진검사에서 반고리관 마비가 확인된 환자들을 대상으 로 하였고, 이는 수평반고리관의 기능 및 연결된 전정신경의 분지 중 위전정신경의 손상을 대변한다. 이에 반해, $\mathrm{CDP}$ 는 전 정척수반사의 기능을 확인하며 반고리관뿐만 아니라 이석기 관의 기능도 연관되어 있어 수평반고리관 외의 수직반고리관 또는 이석기관의 회복에 의해 더 빠른 회복속도를 보일 수 있 을 것으로 추정된다. 또한, $\mathrm{CDP}$ 결과의 회복에 있어 전정척수 반사뿐만 아니라 체성감각, 시각, 전정감각의 재분배(reweighting) 및 중추의 자세 조절 시스템이 관여할 수 있다. ${ }^{10)}$

전정척수반사와 전정안반사의 상관관계를 알아보았을 때, $\mathrm{SOT}$ 총합점수의 호전기간은 온도안진검사의 반고리관 마비
정도뿐 아니라, 자발안진의 크기나 자발안진이 사라질 때까지 의 기간과도 연관성이 없었다. 이는 기존의 연구들과 유사한 결과를 보였다. 한 연구에서 $\mathrm{CDP}$ 와 전기안진검사의 연관성을 확인했을 때, 39 명의 말초성 전정질환 환자들에서 전기안진검 사는 $94 \%$ 에서 비정상이었으나, $\mathrm{CDP}$ 는 $59 \%$ 에서 비정상으로 연관성이 적었다. ${ }^{16}$

위와 같이 $\mathrm{CDP}$ 의 결과가 전정안반사를 평가하는 전정기 능검사의 결과와 약한 연관성을 보이는 이유는 다음과 같이 추정해 볼 수 있다. 첫째, $\mathrm{CDP}$ 는 전정척수반사와 자세제어시 스템을 통한 검사인 반면에 기존의 전정기능검사는 전정안 반사와 안구운동시스템을 이용하는 검사로, 전정기능을 평 가하기 위한 경로가 다르기 때문에 전정기능검사가 비정상 이더라도 $\mathrm{CDP}$ 는 정상일 수 있다. ${ }^{17)}$ 둘째, SOT의 회복기간이 평균 3.7일로 매우 짧기 때문에 전정안반사를 반영하는 전정 기능검사의 결과들과 통계학적으로 의미 있는 상관성을 보여 주기에는 어려움이 있을 수 있다. 마지막으로, 온도안진검사나 회전의자 같은 검사는 수평반고리관을 검사하는 방법이지만 자세변동 같은 간섭을 주는 $\mathrm{CDP}$ 는 수직반고리관뿐만 아니라 다른 이석기관과도 연관이 있기 때문에, $\mathrm{CDP}$ 는 기존의 전정 기능검사와 다른 전정기능을 평가한다는 것이다. 실제로, 기 존의 전정기능검사는 수평반고리관의 기능을 평가하는 것에 국한되어 자세불안정과 같은 균형 장애에 대한 민감도는 떨어 진다.6) 여러 저자들에 의하면 SOT의 민감도는 말초전정장애 에서 15 60\%, 중추성인 경우는 21 100\%에 이른다. ${ }^{16,18-22)}$ 결 국 $\mathrm{AVN}$ 과 같은 급성 말초전정질환 환자에서는 기존의 전정 기능검사와 같이 $\mathrm{CDP}$ 를 같이 시행하여 종합적인 판단을 하 는 것이 필요하다. ${ }^{23)}$

본 연구에서는 첫 진단 시점과 SOT의 총점이 회복된 시점 에 4가지 설문지의 변화를 확인하였으며, 두 시점 사이에 4 가 지 설문지의 점수가 통계적으로 유의하게 회복된 결과를 확 인할 수 있었다. 이는 환자들의 어지럼 발생 후 SOT의 총점 이 회복되는 기간이 평균 $3.7 \pm 2.9$ 일로 매우 짧은 점을 감안 할 때, 환자들의 주관적 증상의 회복이 SOT의 회복시점과 연 관성이 있음을 의미한다. 이러한 결과는 기존의 설문지를 통한 주관적인 어지럼의 정도와 균형 기능의 객관적인 결과 사이 의 상관관계를 분석한 연구와 유사한 결과를 보였다. ${ }^{24)}$ 또한 
$\mathrm{VAS}$ 와 DHI에서 확인할 수 있는 일상생활에서의 어지럼 정도 뿐 아니라, $\mathrm{MSQ}$ 와 $\mathrm{ABC}$ 를 통한 움직임 및 자세불안정의 주 관적 정도 또한 $\mathrm{CDP}$ 의 회복과 연관성이 있다는 것을 의미하 며, $\mathrm{CDP}$ 가 $\mathrm{AVN}$ 환자에서 주관적 어지럼의 회복을 평가하는 데 의미 있는 역할을 한다는 것을 알 수 있었다.

본 연구는 몇 가지 부족한 부분이 있었다. 첫째, SOT 총점 의 회복되는 기간이 너무 짧아서 검사지표들의 통계적 의미를 확인하는 데 한계가 있었다. 특히 초기 SOT의 총점이 낮은 경 우 SOT 총점이 회복되는 기간이 더 길어지는 경향성을 확인 할 수 있었으나, SOT의 회복속도가 매우 짧은 경우가 많아 통계적인 의미를 확인하지 못했다. 둘째, 주관적 어지럼 정도 를 확인하기 위해 설문지를 시행한 시점이다. 일반적으로 증상 발생 후 특정 경과 시점에 설문지 및 SOT의 검사 결과를 통해 상관관계를 확인할 수 있으나, 본 연구를 SOT의 결과를 통해 $\mathrm{CDP}$ 의 자연경과를 확인하기 위해 분석 시점을 $\mathrm{SOT}$ 의 회복 시점으로 정하였다. 셋째, SOT가 전정척수반사를 전부 대변 할 수 없으며, $\mathrm{CDP}$ 는 $\mathrm{AVN}$ 환자들의 일부에서는 정상 소견을 보이는 한계가 있다. 본 연구에서도 $\mathrm{AVN}$ 으로 진단된 62명의 환자들 중 21 명(33.9\%)의 환자에서는 $\mathrm{SOT}$ 의 총점이 정상이 었다. 하지만, 본 연구는 많은 수의 $\mathrm{AVN}$ 환자들에서 전정척 수반사를 대표하는 $\mathrm{CDP}$ 와 전정안반사의 연속적인 변화를 처음으로 전향적으로 연구한 것으로 의미 있는 결과를 보여 주었다.

결론적으로, $\mathrm{AVN}$ 환자들에서 전정척수반사의 회복속도 는 전정안반사의 회복속도에 비해 현저히 빨랐다. 비록 전정 척수반사가 전정안반사의 결과들과 상관관계를 보이지 않았 으나, 전정척수반사의 회복과 함께 $\mathrm{AVN}$ 환자들의 주관적인 어지럼 및 자세불안정의 정도 역시 매우 빠르게 회복되었다. 본 연구의 결과를 통해, $\mathrm{CDP}$ 는 $\mathrm{AVN}$ 환자들에서 단독으로 전정기능의 회복을 대변하기에는 부족함이 있으나, 자세불안 정을 확인할 수 있는 객관적인 검사로서 환자들의 주관적인 어지럼 회복의 정도를 예측할 수 있는 검사이다. 따라서, $\mathrm{AVN}$ 환자들에서 기존의 전정기능검사 결과들과 함께 시행하여 환 자들의 자세불안정 상태를 종합적으로 평가하는 데 매우 유용 한 검사라고 할 수 있다.

\section{Acknowledgments}

This research (2013-01-09) was supported by Research Program for Clinical Professor of Myonji Hospital.

\section{REFERENCES}

1) Cooper CW. Vestibular neuronitis: a review of a common cause of vertigo in general practice. Br J Gen Pract 1993;43(369):164-7.

2) Coats AC. Vestibular neuronitis. Trans Am Acad Ophthalmol Otolaryngol 1969;73(3):395-408.

3) Baloh RW. Clinical practice. Vestibular neuritis. N Engl J Med 2003; 348(11):1027-32.

4) Nashner LM, Peters JF. Dynamic posturography in the diagnosis and management of dizziness and balance disorders. Neurol Clin 1990;8(2):331-49.

5) Cyr DG, Moore GF, Moller CG. Clinical application of computerized dynamic posturography. Entechnology 1988:36-47.

6) Goh EK. Clinical application of computerized dynamic posturography. Res Vestib Sci 2005;4(1):107-18.

7) Jacobson GP, Newman CW. The development of the Dizziness Handicap Inventory. Arch Otolaryngol Head Neck Surg 1990;116(4): 424-7.

8) Powell LE, Myers AM. The Activities-Specific Balance Confidence (ABC) Scale. J Gerontol A Biol Sci Med Sci 1995;50A(1):M28-34.

9) Cohen HS, Kimball KT. Development of the vestibular disorders activities of daily living scale. Arch Otolaryngol Head Neck Surg 2000;126(7):881-7.

10) Fetter M, Diener HC, Dichgans J. Recovery of postural control after an acute unilateral vestibular lesion in humans. J Vestib Res 19901991;1(4):373-83.

11) Kim JY, Hur DG, Jeon SY, Kim JP, Park JJ, Son HY, et al. Assessment of subjective symptoms using Dizziness Handicap Inventory in patients with vestibular neuritis. Res Vestib Sci 2009;8(1):27-31.

12) Han GC, Lee EJ, Lee JH, Park SN, Lee HY, Jeon EJ, et al. The study of standardization for a Korean adaptation of self-report measures of dizziness. Res Vestib Sci 2004;3(2):307-25.

13) Smith-Wheelock M, Shepard NT, Telian SA. Physical therapy program for vestibular rehabilitation. Am J Otol 1991;12(3):218-25.

14) Brodal A. Anatomy of the vestibular nuclei and their connections. In: Kornhuber HH, editor. Handbook of sensory physiology. Berlin: Springer-Verlag;1974. p.239-352.

15) Collewijn H. The vestibulo-ocular reflex: an outdated concept? Prog Brain Res 1989;80:197-209; discussion 171-2.

16) Keim RJ. Clinical comparisons of posturography and electronystagmography. Laryngoscope 1993;103(7):713-6.

17) Furman JM. Role of posturography in the management of vestibular patients. Otolaryngol Head Neck Surg 1995;112(1):8-15.

18) Voorhees RL. Dynamic posturography findings in central nervous system disorders. Otolaryngol Head Neck Surg 1990;103(1):96-101.

19) Asai M, Watanabe Y, Ohashi N, Mizukoshi K. Evaluation of vestibular function by dynamic posturography and other equilibrium examinations. Acta Otolaryngol Suppl 1993;504:120-4.

20) Hamid MA, Hughes GB, Kinney SE. Specificity and sensitivity of dynamic posturography. A retrospective analysis. Acta Otolaryngol Suppl 1991;481:596-600.

21) Parker SW. Vestibular evaluation--electronystagmography, rotational testing, and posturography. Clin Electroencephalogr 1993;24(4): 151-9.

22) Di Fabio RP. Sensitivity and specificity of platform posturography for identifying patients with vestibular dysfunction. Phys Ther 1995; 75(4):290-305.

23) Goebel JA, Paige GD. Dynamic posturography and caloric test results in patients with and without vertigo. Otolaryngol Head Neck Surg 1989;100(6):553-8.

24) Jacobson GP, Newman CW, Hunter L, Balzer GK. Balance function test correlates of the Dizziness Handicap Inventory. J Am Acad Audiol 1991;2(4):253-60. 